\title{
Análise e Fomento ao Uso do Laboratório de Informática na Escola: Um Estudo de Caso
}

\author{
Bruno R. Behnken Costa ${ }^{1}$, Carla A. D. Moreira Delgado ${ }^{1}$, Filipe J. Teixeira de Oliveira ${ }^{1}$ \\ ${ }^{1}$ Departamento de Ciência da Computação \\ Instituto de Matemática - Universidade Federal do Rio de Janeiro (UFRJ) \\ brunobehnken@gmail.com, carla.delgado@gmail.com, filipe.jtoliveira@gmail.com
}

\begin{abstract}
The Educational Informatics is an area recognized as necessary for the modernization of the school and its methods, and the computer can act as a catalyst for the teaching and learning process, if well used. In this context, this paper proposes to analyze the usage and management of the Educational Computer Laboratory of CAp-UFRJ, as well as to promote a better implementation of Educational Informatics in this school; besides identifying, discussing and proposing solutions to existing problems.
\end{abstract}

Resumo. A Informática Educativa é uma área reconhecidamente necessária para a modernização da escola e de seus métodos, e o computador pode atuar como catalisador do processo de ensino e aprendizado, se bem utilizado. Neste contexto, este trabalho se propõe a analisar o uso e a gestão do Laboratório de Informática Educativa do CAp-UFRJ, bem como a fomentar uma melhor implementação da Informática Educativa neste colégio; além de identificar, discutir e propor soluções para problemas existentes.

\section{Introdução}

O laboratório de informática do CAp-UFRJ (Colégio de Aplicação da Universidade Federal do Rio de Janeiro) foi reaberto no ano de 2016, e desde então o seu uso livre é permitido aos estudantes do Ensino Médio e Fundamental II. A intenção é que os alunos usem os equipamentos para atividades escolares ou estudos de seu interesse, entretanto, percebeu-se que o uso livre do laboratório é majoritariamente para jogos de entretenimento. Considerando que o uso do computador é, por si só, positivo, canalizar tal uso para atividades com foco educacional pode favorecer a melhor compreensão, por parte do aluno, do potencial do computador para o estudo e para a construção do conhecimento.

\subsection{Objetivos e Metodologia da Pesquisa}

Este trabalho tem a proposta de conhecer melhor o laboratório do CAp-UFRJ e a sua dinâmica de uso, e tem o objetivo de, a partir deste conhecimento, propor discussões e possíveis soluções para dificuldades e problemas encontrados. Em suporte a este objetivo, como proposta secundária, tentamos ministrar uma aula em parceria com uma professora de matemática utilizando um software educacional. A metodologia será pesquisa-ação, onde pretende-se diagnosticar a dinâmica de uso do LIE do CAp-UFRJ fazendo uso de métodos etnográficos, observação participante, questionários e entrevistas com gestores, professores e bolsistas. 
VIII Congresso Brasileiro de Informática na Educação (CBIE 2019)

Anais do XXV Workshop de Informática na Escola (WIE 2019)

\section{Referencial Teórico}

Na sociedade contemporânea, é notória a influência que exerce a tecnologia. Diante de um cenário de constante mudança, é natural que as instituições mais tradicionais tenham dificuldades em acompanhar a rápida evolução das NTIC. Neste contexto, a situação da escola é delicada pois ela lida diretamente com jovens que possuem amplo acesso a tecnologias de ponta e jovens que possuem pouco ou nenhum acesso à tecnologia.

\subsection{A Importância da Informática Educativa}

O computador é uma ferramenta poderosa, que em muito pode contribuir para a pedagogia. "Entretanto, constata-se em algumas realidades escolares, a ausência de uma visão mais ampliada da utilização do computador enquanto um mediador na construção de conhecimentos" [Carvalho and Monteiro 2012].

Neste contexto, "o uso das NTIC no ensino constitui em um dos aspectos considerados importantes para a modernização da escola e da educação. A essas tecnologias é depositada a possibilidade de transformar o ensino, de dar mais autonomia ao aluno, alterando a relação professor-aluno e aponta ( $\mathrm{sic}$ ) para mudanças na estrutura e funcionamento da escola" [Dutra 2010]. Entretanto, "enquanto a sociedade muda e experimenta desafios mais complexos, a educação formal continua, de maneira geral, organizada de modo previsível, repetitivo, burocrático, pouco atraente" [Moran et al. 2013].

O Laboratório de Informática Educativa (LIE) é necessário, entretanto não é suficiente para uma implementação eficiente da IE. Sobre isso, afirma [Odorico 2012] que "muitas instituições que inseriram Laboratórios de Informática em seu meio não conseguiram realizar as modificações esperadas, sendo estes espaços considerados na maioria dos casos enfeites". Ao tomarmos consciência de tal realidade, é natural que busquemos as razões que levam a isto. A literatura aponta que as mais relevantes razões pelas quais a IE não é bem implementada mesmo com a presença do LIE são a resistência inicial dos professores da escola e a ausência do docente do LIE.

É necessário ter em mente que "o professor tem a responsabilidade de preparar o aluno para se tornar um cidadão ativo dentro da sociedade, apto a questionar, debater e romper paradigmas" [Oliveira 2014]. No âmbito tecnológico-escolar, o papel do professor é, portanto, preparar seus alunos para a utilização das tecnologias, familiarizando-os com elas e dando subsídios para que estes alunos, no futuro, sejam capazes de aprender por si mesmos a utilizá-las conforme sentirem necessidade.

É fundamental que esteja presente um ator conhecido como "docente do LIE". Este professor possui formação tanto técnica quanto pedagógica, e está capacitado para auxiliar os demais atores (gestores e outros professores) na elaboração e execução de atividades pedagógicas no contexto da Informática Educativa. A despeito de sua importância, muitas vezes o docente do LIE não está presente nas escolas. Odorico constatou que "um fator que pesa muito na utilização dos laboratórios é a presença na escola de um profissional da área de informática, já que muitos professores sentem-se inseguros e apresentam dificuldades para utilizar o computador. Entretanto nenhuma das instituições analisadas possui tal profissional para auxiliar os professores nas matérias específicas" [Odorico 2012]. 
VIII Congresso Brasileiro de Informática na Educação (CBIE 2019)

Anais do XXV Workshop de Informática na Escola (WIE 2019)

\section{Entrevistando Atores para Compreender o Funcionamento do Laboratório}

Para melhor compreender a dinâmica de funcionamento interno do CAp, optamos por realizar entrevistas com alguns atores que consideramos como fundamentais para o funcionamento efetivo de um LIE. No caso do CAp, esses atores são a Direção Geral (DG), como gestora de recursos financeiros e da escola como um todo; a Direção Adjunta de Licenciatura, Pesquisa e Extensão (DALPE), como setor responsável pelos recursos pedagógicos da escola, inclusive pelo laboratório; a Prof ${ }^{\mathrm{a}}$. Cassandra, que, ao conhecer nosso trabalho, se interessou pela proposta e aceitou utilizar o laboratório com o nosso suporte; e dois bolsistas, cuja função é permanecer no laboratório e auxiliar as atividades desenvolvidas nele.

A partir das entrevistas foi possível observar a situação atual do CAp, entender a dinâmica de funcionamento do laboratório, obter subsídios para o trabalho que realizamos a seguir (de tentativa de utilização pedagógica do LIE) e tirar algumas conclusões sobre os problemas existentes atualmente. A transcrição das entrevistas foge ao escopo deste artigo, entretanto está disponível para consulta em [Costa and Oliveira 2019].

O LIE do CAp não possui o seu próprio docente, ator classificado como indispensável por [Chagas 2003]; entretanto, esta função é, até certo ponto, desempenhada por bolsistas da própria UFRJ. Entretanto, pudemos perceber que a presença dos bolsistas não é suficiente para fomentar a implementação da Informática Educativa, fato evidenciado nas duas entrevistas realizadas com os gestores, que demonstraram desejo de que o laboratório fosse mais utilizado para fins pedagógicos, tanto no contexto de cada disciplina isolada quanto no contexto do colégio como um todo.

Fica evidente que os bolsistas não têm possibilidade de desenvolver projetos na área de IE, ainda que estes queiram fazê-lo (esta vontade se mostrou presente nas entrevistas) e, por conta da ausência do docente do LIE, os bolsistas acabam também assumindo encargos que não deveriam (e talvez nem poderiam) ser seus, tais como a manutenção de hardware e software das máquinas no laboratório, bem como a responsabilidade de decidir se um software deve ou não ser instalado no computador ou se um site ou software deve ser acessado ou não pelos alunos.

\section{A Tentativa de Aula com a Prof ${ }^{\mathrm{a}}$. Cassandra}

A parte prática deste trabalho se deu através de uma tentativa de aula no LIE do CApUFRJ em parceria com a Prof ${ }^{\mathrm{a}}$ Cassandra. Nesta aula, seria ministrado o conteúdo de frações a uma turma do quinto ano fundamental, com apoio do software educacional JFractionLab. Entretanto, no dia acordado para o ministério da aula foram encontrados diversos problemas que, em série, culminaram na impossibilidade de realizá-la.

O relato completo foge ao escopo deste artigo, entretanto está disponível para consulta em [Costa and Oliveira 2019]. Aqui, limitamo-nos a expor os problemas que encontramos, pois eles subsidiam as discussões nas quais culminaram nossa pesquisa.

Dentre os principais problemas percebidos e vivenciados por nós, que se relacionam mais fortemente com a dinâmica do laboratório como recurso pedagógico da escola, destacamos o atraso da bolsista, que chegou 45 minutos após o horário convencionado para a sua chegada; a impressora quebrada, que impede o atendimento à forte 
VIII Congresso Brasileiro de Informática na Educação (CBIE 2019)

Anais do XXV Workshop de Informática na Escola (WIE 2019)

demanda de impressões que chega ao laboratório; o fato de apenas um bolsista possuir a senha de administrador das máquinas do laboratório; a falta de preparo técnico dos bolsistas; e as requisições de instalação de software serem avaliadas por um bolsista.

Os dois últimos pontos fornecem um contraste interessante, pois a equipe de bolsistas é multidisciplinar. Enquanto uns possuem preparo técnico suficiente para "justificar" a responsabilidade de avaliar requisições de instalação de software, outros possuem formação pedagógica mais forte, em detrimento da formação técnica. Fica evidente a tentativa, por parte da gestão escolar, de contornar a ausência do docente do LIE.

\section{Discussões, Propostas e Contribuição Final}

Refletindo sobre os problemas expostos, chegamos à conclusão de que os que são de ordem técnica e pedagógica seriam sanados, ou pelo menos amenizados, com a presença do "docente do LIE", um professor com formação tanto pedagógica quanto computacional, alocado para se responsabilizar pelo LIE e para transformar o laboratório em um verdadeiro recurso pedagógico no colégio.

Nesse contexto, o docente do LIE é responsável tanto pela manutenção do espaço e dos recursos tecnológicos quanto pela elaboração de projetos pedagógicos do laboratório, em consonância com o projeto pedagógico do colégio. O docente do LIE é responsável, ainda, por oferecer suporte tanto técnico quanto pedagógico aos professores que utilizarem o laboratório. Atualmente, no CAp, esse suporte, quando existe, é ineficaz; e o projeto pedagógico do laboratório é inexistente. Em poucas palavras, o docente do LIE é responsável por fazer a conexão entre as disciplinas do currículo regular e os recursos tecnológicos presentes no colégio.

A partir das dificuldades encontradas pudemos perceber que o uso do LIE é uma tarefa relativamente complicada e difícil mesmo para os docentes da própria instituição, que, além de não encontrarem suporte extensivo do ponto de vista técnico e pedagógico, ainda precisam lidar com dificuldades que acabam se tornando barreiras à utilização do laboratório, e que atuam, naturalmente, como fator desmotivador a esta utilização.

Percebemos, assim, que fomentar o uso do laboratório por parte dos docentes é um objetivo mais importante do que pensáramos a princípio, e que esse fomento deve começar com a tentativa de amenizar as dificuldades que o laboratório enfrenta e, assim, suavizar as barreiras nas quais estas se constituem.

Conforme dito, chegamos à conclusão de que a maioria das dificuldades seria sanada, ou pelo menos amenizada, com a presença do "docente do LIE" no laboratório do CAp. Neste sentido, optamos por elaborar uma conclusão atendendo melhor ao objetivo de fomentar o uso do LIE entre os docentes do CAp-UFRJ.

Mediante sugestão nossa, a DALPE mostrou-se favorável à possibilidade de contratar um novo funcionário para assumir a posição de docente do LIE. Neste contexto, para dar suporte a esta contratação, decidimos por concluir o trabalho delineando os encargos, a formação acadêmica necessária e a carga horária relacionados à função de docente do LIE, bem como tecer considerações a respeito de como deve se dar a sinergia entre este e os demais atores. A transcrição completa desta contribuição foge ao escopo deste artigo, estando disponível em [Costa and Oliveira 2019]. 
VIII Congresso Brasileiro de Informática na Educação (CBIE 2019)

Anais do XXV Workshop de Informática na Escola (WIE 2019)

\section{Conclusão e Considerações Finais}

Embora o ministério da aula de matemática no laboratório não tenha sido possível, acreditamos que pudemos dar boas contribuições para o CAp. Foi-nos relatado pela DALPE que já está em estudo a possibilidade de realização de workshops para os professores a respeito do uso do laboratório na educação, com propostas pedagógicas que utilizem a informática, e que essa proposta surgiu em reuniões e discussões que foram desdobramentos das nossas visitas ao CAp e das entrevistas que realizamos com os atores envolvidos no laboratório.

Além disso, a demanda pelo docente do LIE nos foi apresentada nas entrevistas aos gestores antes mesmo de concluirmos que este era o ator que faltava para um melhor funcionamento do laboratório. A conclusão deste trabalho, que apresenta o delineamento dos encargos do docente do LIE e a formação acadêmica necessária para exercer esta função, é uma contribuição importante pois fornece embasamento técnico a um eventual pedido de contratação de funcionário para ocupar esta função; bem como fornece embasamento bibliográfico consagrado, uma vez que o plano de ação encontra sustento no sólido referencial teórico apresentado.

Acreditamos, por fim, que nosso trabalho pode ser de utilidade e relevância para outras instituições que, conforme constatado no referencial teórico, enfrentam problemas semelhantes aos que encontramos e vivenciamos no CAp-UFRJ.

\section{References}

Carvalho, L. M. T. L. d. and Monteiro, C. E. F. (2012). Reflexões sobre implementação e uso de laboratórios de informática na escola pública. Revista Roteiro, 37(2):343-360.

Chagas, Z. B. d. e. a. (2003). Um retrato dos docentes dos laboratórios de informática educativa das escolas municipais de fortaleza. Anais do XVI Encontro de Pesquisa Educacional do Norte e Nordeste: Educação, Desenvolvimento Humano e Cidadania, page 625 .

Costa, B. R. B. and Oliveira, F. J. T. d. (2019). Análise e Fomento ao Uso do Laboratório de Informática na Escola: Um Estudo de Caso. Trabalho de conclusão de curso, Universidade Federal do Rio de Janeiro.

Dutra, A. F. (2010). O Professor Orientador de Informática Educativa - POIE das Escolas do Município de São Paulo. Dissertação de mestrado, Universidade de São Paulo.

Moran, J. M., Masetto, M. T., and Behrens, M. A. (2013). Novas Tecnologias e Mediação Pedagógica. Editora Papirus, 21 edition.

Odorico, E. K. e. a. (2012). Análise do não uso do laboratório de informática nas escolas públicas e estudo de caso. Anais do XVIII Workshop de Informática na Escola.

Oliveira, W. M. d. (2014). Uma abordagem sobre o papel do professor no processo ensino/aprendizagem. Disponível em: https://www.inesul.edu.

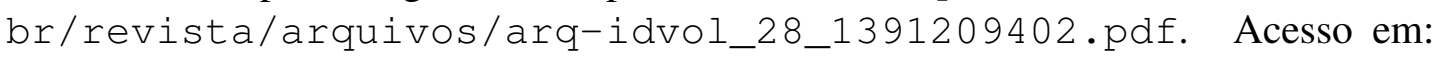
23/02/2019. 